\title{
Radiological abnormalities in infants with urinary tract infections
}

\author{
D BOURCHIER, G D ABBOTT, AND T M J MALING
}

Departments of Paediatrics and Radiology, Christchurch Hospital, Christchurch, New Zealand

SUMMARY An intravenous urogram and micturating cystourethrogram were carried out in 100 infants presenting with documented urinary tract infections. Ninety three cases were identified by suprapubic aspiration and 7 by culture of two voided urine samples containing greater than $100 \times 10^{6}$ organisms per litre. The urinary tract abnormalities were analysed in respect of their clinical importance, patient's age, sex, and prematurity (in the 10 preterm infants).

Radiological abnormalities were found in $47 \%$ of the infants ( $40 \%$ of boys; $63 \%$ of girls). Twenty nine per cent of the infants had a urinary tract abnormality regarded as clinically important-namely grade 3 or 4 vesicoureteric reflux, reflux nephropathy, or obstructive lesions requiring surgery. Six of the 10 preterm infants had radiological abnormalities. Spontaneous resolution or improvement occurred within 6 months of birth in three of the four preterm infants with severe vesicoureteric reflux.

Urinary tract infections in infancy are frequently associated with an underlying abnormality of the urinary tract. ${ }^{1}$ Smellie, ${ }^{2}$ Littlewood, $^{3}$ and Bergstrom ${ }^{4}$ have reported the frequency and characteristics of urinary tract infections in infancy, but in these studies the use of bag urine specimens rather than suprapubic aspirates to document the infection may have led to over diagnosis, as it is now recognised that bag or single 'clean-catch' specimens are unreliable as determinants of urinary tract infection in infancy. ${ }^{5}$

Recently Ginsburg and McCracken ${ }^{6}$ reported a series of 100 infants with urinary tract infections diagnosed by suprapubic aspiration. They confirmed that, particularly in the first three months of life, boys were more often infected but in contrast with other published series ${ }^{12}$ they reported a remarkably low number of urinary tract abnormalities.

This paper reports the frequency of urinary tract abnormalities in 100 infants with documented urinary tract infection with particular reference to prematurity, age, sex, and clinical importance of the radiological findings.

\section{Methods}

Patients. Over an 11 year period (1972 to 1982 inclusive), 111 infants aged under 1 year were diagnosed as having a first urinary tract infection.
Eleven of these infants were excluded from the study either because of an insecure diagnosis of urinary tract infection (for example, single bag urine sample only) or because of incomplete radiological evaluation. The infants were investigated for urinary tract infection if there was clinical suspicion of this diagnosis; they were not part of a screening survey. Ten of the remaining 100 infants were preterm, with gestational ages ranging from 27 to 36 weeks.

Diagnosis of urinary tract infection. Urinary tract infection in 93 infants was diagnosed when there was a growth of organisms in urine obtained by suprapubic aspiration. The remaining 7 infants had a pure growth of a single organism (greater than $100 \times 10^{6}$ organisms/l) from a bag urine sample on two consecutive specimens together with appreciable pyuria (white blood cells $>10 / \mathrm{mm}^{3}$ ).

Radiology. Three to four weeks after appropriate antimicrobial treatment of their urinary tract infections all patients had both an intravenous urogram and a micturating cystourethrogram.

\section{Intravenous urogram}

Patients under 6 months of age had no prior preparation, while those between 6 and 12 months had a mild bowel preparation 12 hours before the examination. In all intravenous urograms a dose of 
contrast medium of 1 to $2 \mathrm{ml} / \mathrm{kg}$ body weight was given intravenously: the contrast medium contained iodine, $325 \mathrm{mg} / \mathrm{ml}$. The examination was regarded as adequate only when the entire renal outline was visualised.

Obstruction was diagnosed when there was uniform dilatation of the calyces, associated with dilatation of the renal pelvis or both the renal pelvis and ureter, depending upon the site of obstruction.

A diagnosis of reflux nephropathy was made when the intravenous urogram showed focal or generalised renal scarring (a scar being loss of depth of the renal parenchyma) and dilatation of the associated calyx or calyces.

\section{Micturating cystourethrogram}

All micturating cystourethrograms were performed by filling the bladder with a $20 \%$ solution of water soluble contrast medium to which kanamycin had been added. Access to the bladder was obtained where possible by suprapubic bladder puncture with a $20 \mathrm{FG}$ angiocath but in those few instances where suprapubic puncture was unsuccessful, filling was via an 8 FG urethral catheter. The bladder was filled by gravity from a reservoir $60 \mathrm{~cm}$ above the patient's bladder. Abdominal radiographs were taken during bladder filling and during micturition.

Classification of vesicoureteric reflux

Where vesicoureteric reflux was found during the micturating cystourethrogram it was classified into one of four grades:

Grade 1-incomplete filling of a normal calibre ureter.

Grade 2-complete ureteric filling but without dilatation.

Grade 3-reflux causing some dilatation of the minor calyces but where a papillary impression still remained.

Grade 4-dilatation of the minor calyces such that no papillary impression could be observed.

\section{Important radiological anomalies}

Important lesions were considered to be present in infants if there was grade 3 or 4 vesicoureteric reflux, reflux nephropathy, or obstructive uropathy requiring surgical correction or close medical supervision and antimicrobial treatment.

\section{Results}

Age and sex distribution. Age and sex distribution is shown in Fig. 1. Ages ranged from 5 days to 12 months (median age 3 months). There were 68 boys and 32 girls, with boys accounting for 46 of the 59 $(78 \%)$ patients aged less than 3 months.

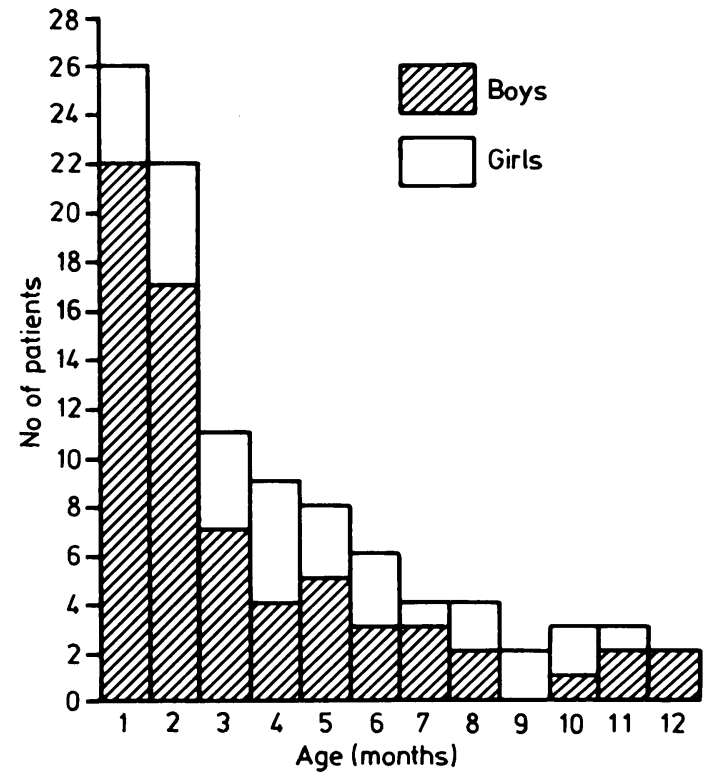

Fig. 1 Age and sex distribution in 100 infants with urinary tract infections.

Radiological abnormalities in the $\mathbf{1 0 0}$ children. Forty seven of the 100 infants had a radiological abnormality (Fig. 2), with 27 of the 68 boys $(40 \%)$ and 20 of the 32 girls $(63 \%)$ affected. Radiological abnormalities occurred in 18 of the 46 boys $(39 \%)$ and five of the 13 girls $(38 \%)$ aged 3 months or less. Nine of the 22 boys $(41 \%)$ and 15 of the 19 girls $(79 \%)$ aged over 3 months had radiological abnormalities.

\section{Intravenous urogram abnormalities}

Seventeen of the 27 infants with an abnormal intravenous urogram had an abnormal micturating cystourethrogram (Fig. 3). Nine of the 10 remaining

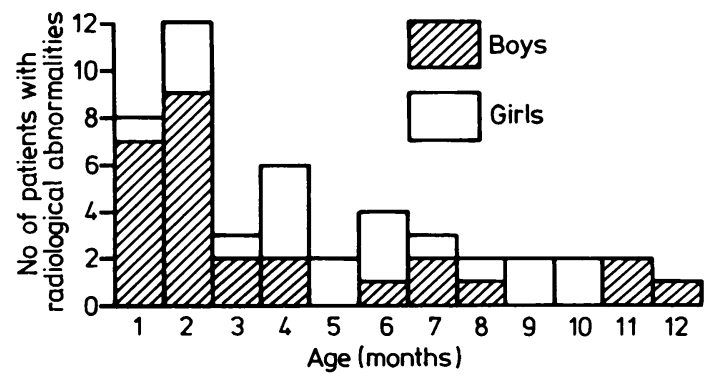

Fig. 2 Radiological abnormalities in 100 infants with urinary tract infections. 


\begin{tabular}{|c|c|c|c|c|c|c|c|c|c|c|c|c|c|}
\hline \multicolumn{14}{|c|}{ Age (months) } \\
\hline IVU abnormality & 1 & 2 & 3 & 4 & 5 & 6 & 7 & 8 & 9 & 10 & 11 & 12 & Total \\
\hline Reflux nephropathy & & $\bullet$ & $\bullet$ & $\bullet$ & - & $\bullet$ & & & - & & & $\bullet$ & 10 \\
\hline $\begin{array}{l}\text { Pelvi-ureteric } \\
\text { dilatation } \\
\text { (a) Unobstructed } \\
\text { (b) Obstructed } \\
\text { - Ureterocoele } \\
\text { - Achalasia } \\
\text { - Duplex system }\end{array}$ & • & $\bullet$ & & • & - & • & & & & $\theta$ & • & & $\left.\begin{array}{l}5 \\
1 \\
3 \\
2\end{array}\right\} 11$ \\
\hline $\begin{array}{l}\text { Other } \\
\text { (a) Unobstructed } \\
\text { duplex system } \\
\text { (b) Renal agenesis } \\
\text { (c) Displaced kidney } \\
2^{\circ} \text { to adrenal } \\
\text { haemorrhage }\end{array}$ & $\bullet$ & $\bullet-$ & & & • & & & & & & & & $\left.\left.{ }^{3}\right\}_{1}\right\}_{6}$ \\
\hline Total & 2 & 8 & 2 & 4 & 3 & 4 & 0 & 0 & 1 & 1 & 1 & 1 & 27 \\
\hline
\end{tabular}

Fig. 3 Intravenous urogram (IVU) abnormalities in 100 infants with urinary tract infections.

\begin{tabular}{|c|c|c|c|c|c|c|c|c|c|c|c|c|c|}
\hline & & & & ge & imo & nth: & & & & & $\begin{array}{l}=\mathrm{Bo} \\
=\mathrm{Gi}\end{array}$ & & \\
\hline MCU abnormality & 1 & 2 & 3 & 4 & 5 & 6 & 7 & 8 & 9 & 10 & 11 & 12 & Total \\
\hline $\begin{array}{l}\text { Vesicoureteric } \\
\text { reflux }\end{array}$ & & & & & & & & & & & & & \\
\hline Grade 1 & - & $\infty$ & & - & & - & & $\bullet$ & & & & & 6 \\
\hline Grade 2 & - & - & & & & - & $\infty$ & - & - & & & & 7 \\
\hline Grade 3 & & & & $\bullet$ & & & & & & - & • & & 6 \\
\hline Grade 4 & - & & & • & - & •. & - & & - & - & - & - & 17 \\
\hline Urethral valves & & & - & & & & & & & & & & 1 \\
\hline Bladder diverticulum & & - & & & & & & & & & & & 1 \\
\hline Total & 6 & 7 & 4 & 3 & 2 & 4 & 3 & 2 & 2 & 2 & 2 & 1 & 38 \\
\hline
\end{tabular}

Fig. 4 Micturating cystourethrogram (MCU) abnormalities in 100 infants with urinary tract infections. 
patients showed reflux nephropathy having ipsilateral, grade 4 vesicoureteric reflux.

\section{Micturating cystourethrogram abnormalities}

Fourteen of the 38 infants with an abnormal micturating cystourethrogram had an abnormal intravenous urogram. Eleven of the 17 infants with grade 4 reflux had an abnormal intravenous urogram (reflux nephropathy in 9 infants) and 13 of the 17 infants with bilateral vesicoureteric reflux had grade 3 or 4 reflux in one or both ureters (Fig. 4).

\section{Important radiological abnormalities}

Twenty nine of the 100 infants had an important abnormality as previously defined-viz grade 3 or 4 reflux, reflux nephropathy, or obstruction requiring surgery (Fig. 5).

Radiological abnormalities in preterm infants. Six of the 10 preterm infants had radiological abnormalities at the initial investigation (Table). Four of the infants had grade 3 or 4 reflux. In three of the four infants spontaneous resolution or improvement of the reflux was seen within 6 months of birth, at the time of the repeat micturating cystourethrogram examination.

Two of the infants who initially had grade 3 or 4 reflux showed no evidence of reflux nephropathy on repeat intravenous urogram examination at 18 months of age (the remaining two patients have not yet had a repeat intravenous urogram).
Table Radiological abnormalities in 6 of 10 preterm infants with urinary tract infections

\begin{tabular}{|c|c|c|c|c|}
\hline $\begin{array}{l}\text { Gestation } \\
\text { (w'ks) }\end{array}$ & $\begin{array}{l}\text { Age at } \\
\text { first } M C U \\
\text { (wks) }\end{array}$ & $\begin{array}{l}M C U \text { findings } \\
\text { (grade) }\end{array}$ & $\begin{array}{l}\text { Age at } \\
\text { repeat MCU } \\
\text { (mths) }\end{array}$ & $\begin{array}{l}M C U \text { findings } \\
\text { (grade) }\end{array}$ \\
\hline 30 & 9 & Left VUR (2) & - & - \\
\hline 32 & 2 & Left VUR (3) & 3 & Normal \\
\hline 35 & 6 & Right VUR (4) & 4 & Normal \\
\hline 32 & 4 & $\begin{array}{l}\text { Right VUR (4) } \\
\text { Left VUR (2) }\end{array}$ & 6 & $\begin{array}{l}\text { Right VUR (4)* } \\
\text { Left VUR (2) }\end{array}$ \\
\hline 30 & 10 & $\begin{array}{l}\text { Right VUR (3) } \\
\text { Left VUR (4) }\end{array}$ & 5 & $\begin{array}{l}\text { Right normal } \\
\text { Left VUR (3) }\end{array}$ \\
\hline $27^{\circ}$ & 12 & $\begin{array}{l}\text { Bladder } \\
\text { diverticulum }\end{array}$ & 10 & $\begin{array}{l}\text { Bladder } \\
\text { diverticulum }\end{array}$ \\
\hline
\end{tabular}

${ }^{*}$ Right ureter subsequently reimplanted.

Associated right renal agenesis.

VUR=vesicoureteric reflux: $M C U=$ micturating cystourethrogram

\section{Discussion}

It has been the policy at this hospital for many years to investigate radiologically all infants and children with their first adequately documented urinary infection. The proportion of infants with underlying abnormalities of the urinary tract has remained constant in this population- $49 \%$ and $47 \%$ in $1972^{1}$ and 1982 respectively. The distribution of abnormalities is also similar with vesicoureteric reflux or reflux nephropathy, or both, accounting for $77 \%$, obstructive lesions contributing $15 \%$, and a miscellaneous group of conditions comprising the remaining $8 \%$. Similar abnormality rates and distribution of abnormalities have been published previously for

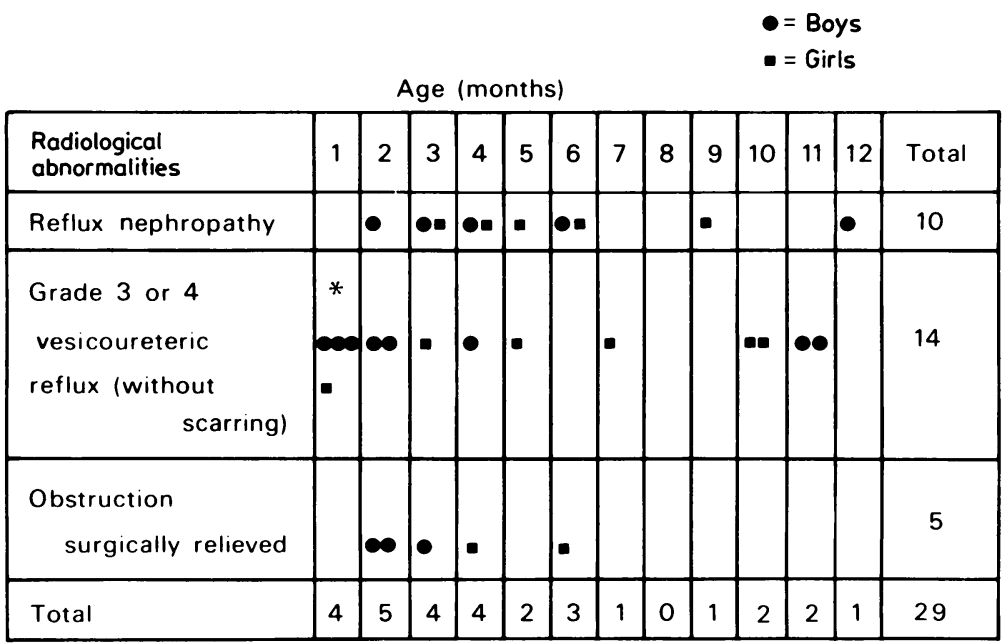

* All preterm infants

Fig. 5 Important radiological abnormalities in 100 infants with urinary tract infections. 
neonates, ${ }^{4}$ infants, ${ }^{1}$ and children. ${ }^{2} 7$ Twenty nine per cent of the described abnormalities in this study were considered important in that they required early surgery or were associated with a high risk of developing reflux nephropathy. The previously described predominance in boys ${ }^{16}$ was confirmed, being most pronounced in those less than 3 months old.

The 10 preterm infants have been considered separately. Although their number was small, 6 of the $10(60 \%)$ had an abnormal urinary tract when investigated radiologically at or near term. Five had vesicoureteric reflux, which was grade 3 or 4 in four, and the remaining infant had an absent right kidney and a bladder diverticulum. Three to 6 months after birth a repeat micturating cystourethrogram examination in these four preterm infants with severe vesicoureteric reflux showed no reflux in two and considerable improvement in the third. The fourth patient continued to have grade 4 reflux and surgical reimplantation of the ureter was undertaken. Grade 4 vesicoureteric reflux is less likely to disappear spontaneously and resolution usually takes years rather than a few months. ${ }^{8}$ It is this form of reflux which has been shown to be associated with progressive renal damage, usually in association with urinary infection. ${ }^{8}$ While management remains controversial, surgical reimplantation of ureters may be employed. The preterm infants studied showed rapid resolution of severe reflux within a short period of time and we would therefore suggest that caution be observed when considering these infants for ureteric implantation in the first few months of life.
We have sought to emphasise the necessity of performing radiological investigations in all infants with a documented urinary tract infection. Twenty nine per cent of term and up to $40 \%$ of preterm infants were found to have appreciable underlying urinary tract pathology.

We thank Professor F T Shannon and Mr C U McRac for their comments and advice on presentation.

\section{References}

1 Shannon FT. Urinary tract infection in infancy. NZ Med J 1972:75:282-4.

2 Smellic JM, Hodson CJ, Edwards D. Normand ICS. Clinical and radiological features of urinary infection in childhood. $\mathrm{Br}$ Med J 1964:ii:1222-6.

3 Littlewood JM. 66 infants with urinary tract infection in first month of life. Arch Dis Child 1972:47:218-26.

+ Bergstrom T. Larson H. Lincoln K. Winberg J. Studies of urinary tract infections in infancy and childhood-eighty consecutive patients with neonatal infection. J Pediatr 1972;80: 858-66.

5 Abbott GD. Neonatal bacteriuria-the value of bladder puncture in resolving problems of interpretation arising from voided urine specimens. Aust Paediatr J 1978:14:83-6.

- Ginsburg CM, McCracken GH. Urinary tract infections in young infants. Pediatrics 1982:69:409-12.

7 Saxena SR, Laurence BM. Shaw DG. The justification for early radiological investigations of urinary tract infection in children. Lancet 1975;ii:4(1)3-4.

* Rolleston GL, Shannon FT. Utley WLF. Relationship of infantile vesico-ureteric reflux to renal damage. $\mathrm{Br}$ Med $J$ 1970:i:460-3.

Correspondence (no reprints available) to Dr G D Abbott. Department of Paediatrics, Christchurch Hospital, Christchurch, New Zealand.

Received 26 March 1984 